\section{Edible Horticultural Therapy for the Rehabilitation of Long-term Hospitalized Female Schizophrenic Patients}

\author{
Hui He, Yanwei Yu, and Jiamin Li \\ School of Architecture and Urban Planning, Huazhong University of Science \\ and Technology, Wuhan, Hubei 430074, China; and Hubei Engineering and \\ Technology Research Center of Urbanization, Wuhan, Hubei 430074, China \\ Luyun Hu \\ Psychiatric Rehabilitation Center, Wuhan Wudong Hospital, Ankang Lane \\ No. 46, Wudong Street, Qingshan District, Wuhan, Hubei 430084, China
}

\section{Fan Zhou}

Psychiatry Department, Wuhan Wudong Hospital, Ankang Lane No. 46, Wudong Street, Qingshan District, Wuhan, Hubei 430084, China

Additional index words. Brief Psychiatric Rating Scale, life satisfaction, Life Satisfaction Index A, mental health, Scale of Social Functioning for Psychotic Inpatients, schizophrenia, social function

\begin{abstract}
We quantitatively assessed the effects of a six-session edible horticultural therapy (EHT) program on long-term-hospitalized (LTH) female patients with schizophrenia. A total of 60 patients were enrolled in the project and randomly divided into an experimental group (30 patients, received EHT) and a control group (30 patients, did not receive EHT). The two groups were evaluated before and after EHT using the Brief Psychiatric Rating Scale (BPRS), the Chinese version Scale of Social Functioning for Psychotic Inpatients (SSFPI), and the Life Satisfaction Index A (LSIA). The clinical symptoms of patients with schizophrenia improved significantly and they recovered social function, but there was no significant change in life satisfaction. In the control group, clinical symptoms recovered but there was no improvement in social function and life satisfaction significantly decreased. In addition, patients in the EHT group expressed satisfaction with the program. In conclusion, EHT can improve the clinical symptoms of schizophrenia and promote recovery of social function; however, its impact on life satisfaction remains unclear.
\end{abstract}

Traditional horticultural therapy and diseases. Horticultural therapy is a practice led by trained professionals who use gardening and other tasks to help improve the health of patients. It was used in ancient China and Egypt and emerged before psychiatric strategies in Europe and the United States (Zhang and Liu, 2009). In 1812, Dr. Benjamin Rush, known as the father of American psychiatry, first learned of the positive effects of garden work on patients with mental illnesses. Up to the 1940s, the U.S. military used horticulture to facilitate wound rehabilitation and vocational training activities, and the research and application of horticultural therapy was rapidly

Received for publication 30 Dec. 2019. Accepted for publication 5 Mar. 2020.

Published online 9 April 2020.

F.Z. is the corresponding author. E-mail: 49306849@ qq.com.

This is an open access article distributed under the CC BY-NC-ND license (https://creativecommons. org/licenses/by-nc-nd/4.0/). developed and promoted (American Horticul-

Horticultural therapy has been applied to specific groups to treat various conditions with some success. Studies have shown that horticultural treatment can reduce the severity of depression (Gonzalez et al., 2009), improve social function (Wu et al., 2018a), improve the lives of people with aphasia (Sarno and Chambers, 1997), aid cardiac rehabilitation (Wichrowski et al., 2005), improve the cognitive function and quality of life of dementia patients (Wu et al., 2018b), and promote the recovery of patients with stroke (Lee et al., 2018).

Traditional horticultural therapy and schizophrenia. Schizophrenia is a serious mental illness (Bonnot and Dumas, 2014; Judge et al., 2005) that can cause many chronic symptoms and affect the physical and mental health of patients. Because of the prolonged course of schizophrenia and the need for hospitalization, although a patient's physiological condition may be controlled or even improve, the disease often causes social reduced life satisfaction (Cai and $\mathrm{Li}, 2011$ ). tural Therapy Association, 2019). dysfunction, decreased quality of life, and
Meanwhile, patients are prone to psychological and social disorders (Wu et al., 2016). In addition, some patients experience chronic schizophrenia in psychiatric hospitals in China and require long-term hospitalization because of social, family, and economic factors (Cui et al., 2018). This limits patient recovery and the return to society (Weng et al., 2000). This type of patient requires rehabilitation during long-term hospitalization to recover social function and improve life satisfaction.

The treatment of schizophrenia has mainly focused on improving patients' symptoms, and the primary methods mainly rely on the traditional Western approach of drug administration and physical stimulation. Although these treatments have been used to decrease delusions and hallucinations, $5 \%$ to $15 \%$ of people continue to experience symptoms during treatment and may experience adverse side effects (Liu et al., 2014). For LTH patients with schizophrenia, complications caused by medications include depression, increased body weight, and numb limbs. Doctors and academics are increasingly thinking that it makes more sense to develop new treatments to improve the psychosocial functioning and quality of life of patients with schizophrenia, rather than just treating the positive symptoms (Kurtz et al., 2019). The goal of treatment should be to improve the efficacy and tolerance of drugs and improve patients' social function and quality of life (Burns and Patrick, 2007; Gaszner, 2009).

Horticultural therapy can be used for schizophrenia rehabilitation, but further experiments are required to provide higherquality evidence of progress (Liu et al., 2014). Horticultural therapy has been shown to reduce psychopathological symptoms (Eum and Kim, 2016; Huang, 2017; Oh et al., 2018), improve cognitive function (Kong et al., 2019), reduce anxiety and depression, increase sociability (Son et al., 2004), and improve metabolism in patients with schizophrenia (Zhu et al., 2017). However, few studies have quantified its effects on the recovery of social function, particularly life satisfaction, in patients with schizophrenia.

EHT and schizophrenia. Plants used for horticultural therapy are mostly ornamental flowers and fruits, with no emphasis on the edible nature of the plants. Our clinical observations have indicated that patients with schizophrenia prefer edible plants as materials rather than common flowers and bonsai plants. EHT is a type of horticultural therapy that uses edible plants and includes watching plants, touching plants, tasting plants, smelling plants, and listening to the natural growth of plants, to stimulate the patient's five senses (vision, touch, taste, smell, and hearing) and exploit the healing power of nature (Zhang et al., 2016). Our EHT program aims to address the physiological and psychological problems of the patient. The patient derives a sense of achievement from tending to and harvesting the edible plants. According to preliminary studies, EHT is acceptable and safe for patients and is a suitable treatment for 
LTH patients with schizophrenia in China. In this study, we evaluated the effects of EHT on the rehabilitation of social function in LTH women with schizophrenia.

\section{Materials and Methods}

\section{Participants}

In total, 60 eligible patients were enrolled in the study. All participants and their families (guardians) volunteered to participate in the study and signed a written informed consent. To participate, the patient had to have the ability to complete the experiment. Thirty patients were included in the control group and 30 in the EHT group, all assigned using the random digital table method. One patient in the control group was taken home by her guardian during the experiment. Thus, the final number of patients in the control group was 29.

The inclusion criteria were being female, having schizophrenia/meeting International Classification of Diseases, 10th Revision diagnostic criteria, having a disease course $>3$ years and hospital admission $>2$ years, being able to communicate and express themselves verbally, and having a certain degree of motor ability. Patients with suicidal and/or self-injury behaviors, communication difficulties, pollen/plant allergies, and serious physical diseases were excluded.

We selected long-term inpatients to investigate complications caused by the longterm use of medications (e.g., depression, increased body weight, atrophied limbs), as well as the socioeconomic and familial factors related to the need for such long-term inpatient care, such as the lack of appropriate community-based resources. Despite the state's acknowledgment of the importance of rehabilitating and treating mentally ill individuals, communities do not have the resources to sustain their recovery, which makes it difficult for them to return to society. Finally, because none of the long-term inpatients had undergone short-term, frequent hospitalization, we were able to obtain experimental data that were largely devoid of the effects of potentially confounding factors.

The average patient age was $44.20 \pm$ 13.695 years in the experimental group and $46.66 \pm 13.401$ years in the control group. A pretest indicated no significant differences in age; educational level; or BPRS, SSFPI, or LSIA scores between the groups.

\section{Study design}

The EHT program. A six-session EHT program comprising activities related to the five senses was developed by qualified horticultural therapists, psychotherapists, and psychiatrists that included planting, watering, tasting, and harvesting plants (Table 1). Seasonal plants, such as lettuce (var. ramosa Hort.) and mint (Mentha haplocalyx Briq.), were included in the EHT program. For example, in the first session (Table 1), lettuce was planted and named. Next, each patient's experiences were shared and communicated with others in the program. Through the planting of the lettuce, each patient's tactile and visual senses were stimulated, and physical activity was also undertaken. Through sharing their experiences, the patients enhanced their communication and expression abilities. Each participant had her own lettuce plants. The plants planted during the first session were harvested and tasted during the sixth session. Therefore, the plants had to be safe for the patients to eat and handle, have a short natural life cycle, and be hardy and palatable. For these reasons, lettuce was considered the best plant.

Methods. A six-session EHT program was organized from 21 Oct. 2018 to 1 Dec. 2018. The experimental group participated in the program once a week (60 min on average), whereas the control group did not. During the study period, the medication regimen of the patients was not adjusted. All patients were administered drugs as per their regular prescriptions. The experimental sites were the hospital garden and rehabilitation room of Wuhan Wudong Hospital, Wuhan, Hubei Province, China.

The EHT was developed by qualified horticultural therapists, psychotherapists, and psychiatrists (Table 1). Before the start of the program, all subjects were assessed using the BPRS, SSFPI, and LSIA scales by means of pretesting, and patients' blood pressure and heart rate were measured before each session to determine whether the participants were physically relaxed. Patients in the experimental group performed activities and expressed their experiences within $60 \mathrm{~min}$. During each course, horticultural therapists and volunteers provided guidance to help participants understand and participate in the EHT activities. After completing all courses, all participants were assessed using the BPRS, SSFPI, and LSIA scales. The evaluators were trained psychiatric professionals blinded to the group assignments. The BPRS and SSFPI scales were administered by practicing doctors, whereas the LSIA scale is a self-report scale (if a patient was not able to complete the scale because of having special needs, the scale

Table 1. Six-session EHT program for patients with schizophrenia, based on activities with plants

\begin{tabular}{|c|c|c|c|c|}
\hline Session & Title/topic & Core competencies & Activity content & Edible plant \\
\hline 1 & A good start & $\begin{array}{l}\text { Tactile and visual sense } \\
\text { engagement, physical } \\
\text { activity, communication, } \\
\text { and expression }\end{array}$ & $\begin{array}{l}\text { Plant lettuce and } \\
\text { name the plants } \\
\text { Share experience and } \\
\text { communicate with other patients }\end{array}$ & $\begin{array}{l}\text { Lettuce } \\
\quad \text { (var. ramosa Hort.) }\end{array}$ \\
\hline 4 & $\begin{array}{l}\text { Comprehensive training } \\
\text { in plant inscription } \\
\text { rubbing (i.e., painting } \\
\text { the back of leaves } \\
\text { and then printing the } \\
\text { leaves on a white bag) }\end{array}$ & $\begin{array}{l}\text { Engagement with visual, } \\
\text { tactile, and olfactory } \\
\text { senses, expression } \\
\text { and creativity }\end{array}$ & $\begin{array}{l}\text { Choose a fruit leaf } \\
\text { Create a print } \\
\text { Share experience and communicate } \\
\quad \text { with other patients }\end{array}$ & $\begin{array}{l}\text { Leaves of grapefruit } \\
\quad \text { (Citrus paradisi } \text { Macf.), orange } \\
\quad \text { (Citrus reticulata } \text { Blanco.), pomegranate } \\
\quad \text { (Punica granatum } \text { L.) }\end{array}$ \\
\hline 6 & Harvest and gratitude & $\begin{array}{l}\text { Engagement with sense } \\
\text { of taste, physical } \\
\text { activity, expression, } \\
\text { collaborative work }\end{array}$ & $\begin{array}{l}\text { Harvest own lettuce } \\
\text { Make fruit salad and share } \\
\text { with friends } \\
\text { Share feelings about these } \\
\text { activities with others }\end{array}$ & $\begin{array}{l}\text { Lettuce (var. ramosa Hort.), tomato } \\
\text { (Solanum lycopersicum), mint } \\
\text { (Mentha haplocalyx Briq.) }\end{array}$ \\
\hline
\end{tabular}


was completed by the doctors in consultation with the patient).

\section{Assessments and statistical analyses}

Three scales were used to assess patient recovery levels, including symptoms, social function recovery, and life satisfaction. To assess clinical symptoms of schizophrenia, the BPRS (Wang, 1998) was used. The BPRS is an 18-item rating scale completed by psychiatrists. Each item is rated from 0 (untested) to 7 (very high), with higher scores indicating more severe symptoms.

To assess social functioning, the Chinese version of the 12-item SSFPI (Zhou et al., 2004) was used. Items are rated on a scale of 0 to 4 (total score represented as grades 1 to 5). A total score of more than 38 points indicates that social function is normal (grade 5). A score of 29 to 38 indicates mild social dysfunction (grade 4). A score of 19 to 28 indicates moderate social dysfunction (grade 3). A score of 9 to 18 indicates severe social dysfunction (grade 2), and a score of less than or equal to 8 indicates very severe social dysfunction (grade 1). The higher the score, the better the social function recovery, and the lower the score, the more serious the social deficit.

To assess patients' life satisfaction, we applied the LSIA. Life satisfaction represents people's subjective experience and psychological satisfaction with their life state, and it is an important index of life quality (Shin and Johnson, 1978). It consists of 20 entries, 12 positive and 8 negative, mainly reflecting individual subjective experience of quality of life. Each item is scored as agree (2 points), disagree (0 points), and not easy to say (1 point). The higher the total score, the greater the patient's life satisfaction.

SPSS (version 24.0) software (IBM Corp., Armonk, NY) was used for data analyses. The BPRS, LSIA, and SSFPI scales were used to analyze differences between the groups before and after EHT based on the paired $t$ test. The independent sample $t$ test was used to analyze data between the two groups.

\section{Results}

BPRS. Before EHT, BPRS scores did not differ between the two groups. After EHT, they differed in both groups (Table 2).

SSFPI. Before EHT, SSFPI scores did not differ between the two groups. After EHT, the score was significantly higher in the experimental group; however, the score did not change significantly in controls (Table 3 ). These results indicate that EHT had significant effects on the social function of schizophrenia patients.

LSIA. Because the LSIA is a self-report scale, there were two invalid questionnaires in each group; these were removed before analyses.

Before EHT, LSIA scores did not differ between the two groups. After EHT, the average LSIA score of patients in the experimental group increased (from 22.07 to

Table 2. Effects of the edible horticultural therapy (EHT) program on clinical symptoms of patients with schizophrenia based on Brief Psychiatric Rating Scale (BPRS) scores.

\begin{tabular}{|c|c|c|c|c|}
\hline & \multirow[b]{2}{*}{ Variable } & \multirow{2}{*}{$\frac{\text { EHT group }(\mathrm{n}=30)}{\operatorname{Mean}(\mathrm{sD})}$} & \multirow{2}{*}{$\frac{\text { Control group }(\mathrm{n}=29)}{\text { Mean }(\mathrm{SD})}$} & \multirow[b]{2}{*}{ Significance } \\
\hline & & & & \\
\hline \multirow[t]{4}{*}{$\overline{\mathrm{BPRS}}$} & Before experiment & $35.50(6.268)$ & $37.86(4.381)$ & $0.100^{\mathrm{NS}}$ \\
\hline & After experiment & $31.83(4.698)$ & $37.38(4.617)$ & $0.000 * * *$ \\
\hline & D-value & -3.67 & -0.48 & \\
\hline & Significance & $0.000^{* * *}$ & $0.020 *$ & \\
\hline
\end{tabular}

The paired $t$ test was used to compare pre- and posttest means in each group.

Ns, *, **, ***Nonsignificant or significant at $P \leq 0.05,0.01$, or 0.001 , respectively.

Table 3. Impact of edible horticultural therapy (EHT) on social function of patients with schizophrenia based on Scale of Social Functioning for Psychotic Inpatients (SSFPI) scores.

\begin{tabular}{|c|c|c|c|c|}
\hline & & EHT group $(n=30)$ & Control group $(n=29)$ & \\
\hline & Variable & Mean (SD) & Mean (SD) & Significance \\
\hline$\overline{\text { SSFPI }}$ & Before experiment & $28.37(6.536)$ & $26.17(5.471)$ & $0.168^{\mathrm{NS}}$ \\
\hline & After experiment & $34.87(5.970)$ & $26.07(5.230)$ & $0.000 * * *$ \\
\hline & D-value & +6.5 & -0.1 & \\
\hline & Significance & $0.000 * * *$ & $0.541^{\mathrm{NS}}$ & \\
\hline
\end{tabular}

The paired $t$ test was used to compare pre- and posttest means in each group.

Ns, *,**,***Nonsignificant or significant at $P \leq 0.05,0.01$, or 0.001 , respectively.

Table 4. Impact of edible horticultural therapy (EHT) on life satisfaction of patients with schizophrenia based on Life Satisfaction Index A (LSIA) scale scores.

\begin{tabular}{|c|c|c|c|c|}
\hline & & EHT group $(n=28)$ & Control group $(n=27)$ & \\
\hline & Variable & Mean (SD) & Mean (SD) & Significance \\
\hline LSIA & Before experiment & $22.07(7.393)$ & $19.56(7.002)$ & $0.201^{\mathrm{NS}}$ \\
\hline & After experiment & $23.29(7.586)$ & $16.22(5.774)$ & $0.000 * * *$ \\
\hline & Significance & $0.273^{\mathrm{NS}}$ & $0.000 * * *$ & \\
\hline
\end{tabular}

The paired $t$ test was used to compare pre- and posttest means in each group.

Ns, *,**,***Nonsignificant or significant at $P \leq 0.05,0.01$, or 0.001 , respectively.

23.29), but not significantly. The score of the control group significantly decreased (Table 4), and there was a significant difference between the two groups' scores. Thus, EHT may play a role in maintaining or improving patients' life satisfaction. This also supports the declining trend in life satisfaction of LTH patients with schizophrenia reported by clinicians, and further demonstrates the potential demand for improvement in life satisfaction in patients with schizophrenia.

Participant feedback. After EHT, interviews were conducted with the participating patients, patient guardians, and doctors. Patients generally showed improved cognitive level and social function recovery. They reported feeling relaxed during the therapy and looked forward to the next session, which improved their social skills. Guardians reported that communication and emotional interactions between patients and families significantly improved after the activity, and patients became more talkative and shared more experiences than before. Doctors reported that after EHT, patients' attitudes significantly improved and they more actively cooperated with the treatment.

\section{Discussion}

Schizophrenia is an important mental illness that requires both prevention and treatment. Long-term inpatients have limited social contact and serious social functional defects (Cui et al., 2018). In the World
Federation of Biological Psychiatry Societies guidelines for the treatment of schizophrenia, improving social function is considered the ultimate goal of schizophrenia treatment. Avoiding long-term hospitalization of patients with chronic schizophrenia improves the patients' social function, allowing them to return to society as soon as possible. When the social function of patients is improved, this cannot only alleviate the disease, shorten the course, and improve treatment outcomes, but also decrease the burden on society and patients' families (Shen and Jia, 2013).

Our quantitative data imply that EHT has different degrees of effects on disease improvement, social function recovery, and life satisfaction improvement, showing a significant effect on social function, consistent with a previous study (Kong et al., 2019; Zhu et al., 2016). There were no significant improvements in the life satisfaction of patients, whereas that of controls significantly decreased. Patients indicated that they gradually relaxed physically and mentally during therapy and were full of hope for their future life, which supports the notion that EHT plays a role in maintaining life satisfaction. Long-term hospitalization often leads to a decrease in patients' social functioning and communication ability (Hu et al., 2018), and also has a negative impact on their quality of life (Tasic et al., 2011); the decreased life satisfaction in the control group is consistent with this clinical experience.

Our results confirm that traditional horticultural therapy is helpful for patients, and 
support the targeted healing effects of EHT for LTH patients with schizophrenia. However, further studies on EHT in LTH mental patients are required to compare patients with different treatment durations and optimize the curriculum content.

The natural environment can reduce emotional stress and activate the sympathetic nervous system. People recover faster in green or natural environments than in urban environments (Stephen, 1987). Our results also indicate that EHT can be not only an adjunct to the treatment of mental illness, but from the perspective of disease prevention, edible landscape can be introduced into urban public spaces to create green and healthy healing environments (He, 2019). In addition to relaxing the body and mind to promote health, it can protect against mental illnesses.

Limitations. This research had some limitations. The life satisfaction scale was selfrated by patients, and thus was subjective. Also, considering the safety of the experiment, the sample size was not large enough. Both of these issues may have affected the quality of our results. Also, having only female patients in this study was another limitation. We will include male patients in future studies.

\section{Conclusions}

EHT can improve the clinical symptoms of LTH patients with schizophrenia, improve their recovery of social function, and positively affect life satisfaction. Our results confirm that traditional horticultural therapy, as a nondrug therapy, has a positive effect on patients and is a good supplement to traditional medicine. We also demonstrated targeted healing effects of EHT in LTH patients with schizophrenia. In the future, advancement of EHT could promote comprehensive recovery of LTH patients with schizophrenia.

\section{Literature Cited}

American Horticultural Therapy Association. 2019. Horticultural therapy history and practice. 19 July 2019. <https://www.ahta.org/ what-is-horticultural-therapy $>$.

Bonnot, O. and N. Dumas. 2014. Schizophrenic disorders in adolescence. Rev. Prat. 64:499-504.

Burns, T. and D. Patrick. 2007. Social functioning as an outcome measure in schizophrenia studies. Acta Psychiatr. Scand. 116:403-418.

Cai, G.C. and C.H. Li. 2011. Effect of farming therapy on quality of life of the patients with chronic schizophrenia hospitalizing for a long period. China J. Health Psychology 19:939-941.

Cui, H.M., Y.L. Zhou, G.N. Li, D. Li, B. Sun, and N. Fan. 2018. Social function in long-term hospitalized patients with stable schizophrenia and its influential factors. Chinese J. Nervous Mental Dis. 44:673-677.

Eum, E.-Y. and H.-S. Kim. 2016. Effects of a horticultural therapy program on self-efficacy, stress response, and psychiatric symptoms in patients with schizophrenia. J. Korean Acad. Psychiatr. Mental Health Nurs. 25:48-57.

Gaszner, P. 2009. Complex therapy of schizophrenia. Neuropsychopharmacologia Hungarica 11: 41-45.

Gonzalez, M.T., T. Hartig, G.G. Patil, E.W. Martinsen, and M. Kirkevold. 2009. Therapeutic horticulture in clinical depression: A prospective study. Res. Theory Nurs. Pract. 23:312-328.

Hu, X.L., Y.H. Zhang, Y. Lu, Z. Liang, and J.W. Zhao. 2018. horticultural therapy on the life quality of long-term hospitalized schizophrenia patients. China J. Health Psychology 26:14571461.

He, H. 2019. Edible landscape. Huazhong University of Science and Technology Press, Wuhan, China.

Huang, Y.Y. 2017. Effect of horticultural therapy on long-term inpatients with senile schizophrenia. Nurs. Pract. Res. 14:150-151.

Judge, A.M., D.O. Perkins, J. Nieri, and D.L. Penn. 2005. Pathways to care in first episode psychosis: A pilot study on help-seeking precipitants and barriers to care. J. Ment. Health 14:465469.

Kong, S.L., J.W. Zhao, Y.H. Zhang, B.Y. Guo, and C.Y. Gao. 2019. Influence of horticultural therapy on cognitive function of patients with schizophrenia in a community-based rehabilitation center. Chinese Preventive Medicine 20:342-346.

Kurtz, M.M., S. Gopal, S. John, and R. Thara. 2019. Objective psychosocial function vs. subjective quality-of-life in schizophrenia within 5 -years after diagnosis: A study from southern India. Psychiatry Res. 272:419-424.

Lee, A.Y., S.A. Park, H.G. Park, and K.C. Son. 2018. Determining the Effects of a horticultural therapy program for improving the upper limb function and balance ability of stroke patients. HortScience 53:110-119.

Liu, Y., L. Bo, S. Sampson, S. Roberts, G. Zhang, and W. Wu. 2014. Horticultural therapy for schizophrenia. Cochrane Database Syst. Rev. (5):CD009413.

Oh, Y.-A., S.-A. Park, and B.-E. Ahn. 2018 Assessment of the psychopathological effects of a horticultural therapy program in patients with schizophrenia. Complement. Ther. Med. 36:54-58.

Sarno, M.T. and N. Chambers. 1997. A horticultural therapy program for individuals with acquired aphasia. Act. Adaptation Aging 22:8191.

Shen, D.R. and X.S. Jia. 2013. Effect of farming therapy for rehabilitation of chronic schizophrenic patients. J. Nongken Med. 35:199-201.

Shin, D.C. and D.M. Johnson. 1978. Avowed happiness as an overall assessment of the quality of life. Soc. Indic. Res. 5:475-492.
Son, K.C., S.J. Um, S.Y. Kim, J.E. Song, and H.R. Kwack. 2004. Effect of horticultural therapy on the changes of self-esteem and sociality of individuals with chronic schizophrenia. Acta Hort. 639:185-191.

Stephen, K. 1987. Aesthetics, affect, and cognition: environmental preference from an evolutionary perspective. Environ. Behav. 19:3-32.

Tasic, G., S. Anakiev, D. Milosevic, and M. Cvetanovic. 2011. P03-343 - Analysis of quality of life long-term hospitalized schizophrenic patients. Eur. Psychiatry 26(Suppl 1):1513 (abstr.).

Wichrowski, M., J. Whiteson, F. Haas, A. Mola, and M.J. Rey. 2005. Effects of horticultural therapy on mood and heart rate in patients participating in an inpatient cardiopulmonary rehabilitation program. J. Cardiopulm. Rehabil. 25:270-274.

Wang, M.Y. 1998. Psychosis/schizophrenia scale, p. 81-93. In: Handbook of psychiatric rating scale. Hunan Science and Technology Publishing House, Chang Sha, China.

Weng, Y.Z., S.M. Ma, L. Lu, M.J. Xu, J.C. Du, and R.X. Cui. 2000. Occupational rehabilitation in hospital for patients with chronic schizophrenia. Chinese J. Rehabilitation 15:125-126.

Wu, Q.J., A.X. Xiao, L.Y. Li, L.F. Tan, and R.Z. Li. 2016. Effect of comprehensive rehabilitation therapy on quality of life and social function of schizophrenic patients with long-term hospitalization. J. Bethune Med. Sci. 14:422-424.

Wu, J.C., M.Z. Xiao, Q.H. Zhao, S. Wei, J. Tian, Q.H. Luo, L. Xiao, and P. Wang. 2018a. Effects of horticultural therapy on quality of life and social function in patients with depression. Chinese Nurs. Mgt. 18:48-51.

Wu, H.Y., L. Ma, L. Zhang, M. Cao, and S.Z. Zhang. 2018b. Effects of horticultural therapy on cognitive function and quality of life in patients with mild to moderate Alzheimer disease. Chinese J. Multiple Organ Dis. Elderly 17:197-201

Zhang, J.H. and W. Liu. 2009. Horticultural therapy. Chinese Landscape Architecture 25:19-23.

Zhang, M.M., S. Zhang, Q.Q. Kong, and P.F. Wang. 2016. Planning and design of leisure and health maintenance agricultural garden based on the theory of five senses therapy. J. Zhejiang Agr. Sci. 57:538-541.

Zhou, C.D., S.C. Jia, and J.G. Pu. 2004. A selfdesigned scale for social function in in-patients with psychosis (SSFPI): Preliminary test of reliability and validity. Sichuan Mental Health 03:144-146.

Zhu, S.H., Z.D. Lu, H.J. Wan, and C.Y. Ye. 2017. Effect of horticultural therapy on metabolism indices in in-patients with chronic schizophrenia. Chinese Mental Health J. 31:447-453.

Zhu, S.H., H.J. Wang, Z.D. Lu, H.P. Wu, Q. Zhang, X.Q. Qian, and C.Y. Ye. 2016. Treatment effect of antipsychotics in combination with horticultural therapy on the inpatients with schizophrenia: A randomized, case-controlled study. Shanghai Archives of Psychiatry 28: 195-203. 